\title{
LOS MOVIMIENTOS SOCIALES URBANOS Un análisis de la obra de Manuel Castells
}

\begin{abstract}
MIGUEL MARTÍNEZ LÓPEZ
Universidad de Vigo

PALABRAS CLAVE ADICIONALES

Sociología urbana, Teoría, Contextos.

\section{ADDITIONAL KEYWORDS}

Urban Sociology, Theory, Contexts.

RESUMEN. Se examina aquí el estatuto teórico de la noción de 'movimientos sociales urbanos' (MSU), tomando como eje de discusión las contribuciones de Manuel Castells. En primer lugar, se evalúan las limitaciones que ha alcanzado este campo de investigación en las últimas tres décadas y el problema que se encuentra al explicar las transformaciones de los MSU tradicionales y la aparición de nuevos MSU. En segundo lugar, se exponen las tres etapas teóricas en las que Castells concibió los MSU, desde su caracterización proactiva en el ámbito del consumo colectivo, pasando por la integralidad de las dimensiones (económicas, políticas y culturales) del significado urbano que podían transformar, hasta llegar a su casi disolución conceptual. A continuación se revisan con detalle las críticas que recibieron sus concepciones en cuatro aspectos fundamentales: autonomía de los MSU, análisis de sus efectos, poder explicativo de los contextos relevantes y centralidad analítica de las relaciones internas del movimiento (composición social, organizativa y contexto de redes de relación). En conjunto, en este artículo, se demuestra que algunas de las fructíferas líneas de estudio aportadas por las investigaciones de Castells precisan ser complementadas y refinadas teóricamente con las contribuciones críticas aquí recogidas aun cuando éstas no fueran integradas satisfactoriamente en la evolución conceptual de aquél.
\end{abstract}

ABSTRACT. The notion of 'Urban Social Movements' (USM) is examined here through the work of Manuel Castells. Firstly, we consider the limits reached by this field of research the last three decades in order to explain the transformations experimented by traditional USM and the coming on new ones. Secondly, three theoretical stages in the work of Castells are identified. Thirdly, we revisit the four main critiques directed to Castells on USM: autonomy of USM from other social struggles, the analysis of USM effects, the explanative capacity of relevant social contexts to the USM and the central emphasis given to its internal social relations (social origins, movements organizations and resources, etc.). As a whole, this paper tries to demonstrate that valuable theoretical contributions of Castells must be complemented and modified by these critiques, even when this sociologist did not accept them in a congruent integration.

E-mail: mm@uvigo.es

\section{Revista Internacional de Sociología (RIS)}

Tercera Época, $n^{\circ}$ 34, Enero-Abril, 2003, pp. 81-106. 
RIS

REVISTA INTERNACIONAL DE SOCIOLOCIA

№ 34, Enero-Abril, 2003

MIGUEL MARTINEZ LÓPEZ

\section{INTRODUCCIÓN}

En los estudios sobre los movimientos sociales (MS, desde ahora) de las últimas tres décadas podríamos dibujar una línea ascendente en la que la sociología y los movimientos sociales urbanos (MSU, desde ahora) tuvieron una intensa presencia inicial. Actualmente, podemos encontrar muchas más disciplinas de las ciencias sociales interesadas en los MS en general, habiéndose diluido, en gran medida, la importancia de los urbanos dentro de ese conjunto. En parte ya fue diagnosticado ese cambio a principios de la pasada década (Urrutia, 1992), con especial atención a lo ocurrido en España después de las primeras elecciones democráticas municipales, $\mathrm{y}$ algunos estudios posteriores reconstruyeron esa historia insistiendo en las consiguientes limitaciones de la interacción entre las asociaciones vecinales y las administraciones locales (Navarro, 1998). La proliferación de nuevos MS y nuevas formas de participación urbana dieron lugar, a la vista de las escasas referencias académicas disponibles, a la idea de que los MSU desaparecieron o dejaron de constituir un "problema social". Pero no faltan los estudios que ponen de relieve el continuo activismo de organizaciones ciudadanas preocupadas por materias urbanísticas y de política local (Villasante, 1995). Por ello, se echa en falta, por lo menos en la sociología española, un esfuerzo teórico por entender las transformaciones de los MSU "clásicos" y el sentido de la aparición de "nuevos" MSU, revisando críticamente las aportaciones más relevantes en este campo.

En ese sentido, planteamos aquí la necesidad de reconstruir la agenda de investigación sociológica sobre los MSU, delimitando las acciones colectivas que los especificarían, distinguiendo los problemas y contextos sociales que hacen pertinente su estudio, y afinando las estrategias teóricas y metodológicas con las que conocerlos. En lo que sigue se examinarán las concepciones que ha formulado uno de los sociólogos más influyentes en esta materia, a lo largo de sucesivas obras (Castells, 1972; 1983; 1997). Veremos cómo en esa evolución han ido perdiendo importancia algunas relevantes dimensiones de análisis y, a la vez, no se han integrado de forma satisfactoria las contribuciones críticas que se le dirigieron a las principales tesis de este autor. Con estas notas no pretendemos agotar, ni mucho menos, el perfil teórico del mencionado programa de investigación acerca de los MSU. No obstante, el debate en torno a la obra de Castells facilita la tarea y nos permite definir algunas líneas fructíferas de análisis en vistas de alcanzar ese objetivo.

El artículo se divide en cuatro partes. En el siguiente epígrafe expongo los principales rasgos y problemas conceptuales que existen en torno a la noción de MSU. Se argumentará que la definición de los MSU ha pasado de una unidimensionalidad a otra (de ser valorados según sus efectos transformadores sobre una contradicción principal del capitalismo, a ser considerados dentro de los estrechos límites de las políticas urbanas locales) y que la obra de Castells no es ajena a esa evolución, aunque tuvo la virtud de inaugurar una concepción de lo urbano, 
en cuanto ámbito del consumo colectivo, que ayudó a situar a los MSU en relación a otros MS. En el segundo punto nos detenemos con algo más de detalle en las tres obras de Castells en las que se concibe la "centralidad funcional" de los MSU; su "articulación integral y localista" de procesos económicos, culturales y políticos; y su retraimiento y reactividad generales en las diversas áreas urbanas del mundo y en la perspectiva de la nueva internacionalización del capital. En el tercer y cuarto epígrafes se examinan algunas de las críticas, a menudo obliteradas, que recibieron las concepciones de Castells sobre los MSU. En particular nos fijaremos en los problemas de: 1) la autonomía de los MSU con respecto a otros conflictos sociales (de clase, de género, etc.); 2) la focalización de los análisis sobre los efectos y fuerza transformadora de los MSU, que derivó en discutibles clasificaciones de los distintos MSU; 3 ) el manejo de los contextos sociales para explicar los procesos sociales en los que está implicado un MSU; y 4) la reḩabilitación de la composición de clase social en el análisis de los MSU, pero en relación directa a la diversidad y contradicciones organizativas de su interior.

\section{LOS MSU: LA REPRODUCCIÓN, LA CIUDAD Y LO LOCAL}

Se debe a la renovación marxista de los estudios urbanos el que, durante los años '70 del pasado siglo, se considerase a las luchas urbanas populares en un plano de igualdad, unas veces, y de complementariedad, otras, con las luchas de clases. La horizontalidad se percibía cuando los efectos de las reivindicaciones por una "mejor ciudad" incidían en las desigualdades económicas y en las asimetrías políticas generales, de la misma forma que lo intentaban o conseguían las luchas obreras. La complementariedad se encontraba cuando se aceptaba una cierta "división del trabajo": el sindicalismo de clase trataría de conseguir cambios en el campo de la producción, mientras que el asociacionismo vecinal o urbano $(\mathrm{o}$, también conocido como "sindicalismo del consumo colectivo") se especializaría en el ámbito de la reproducción de la fuerza de trabajo (Lojkine, 1977; Urrutia, 1999).

Los MSU aparecían, entonces, como fenómenos centrales del cambio social, como MS proactivos. Para conceptualizarlos teóricamente se partió de la mencionada noción sobre "lo urbano", además de un marco en el que establecer la autonomía, incidencia, particularidades, etc. de la política local (el ámbito municipal o metropolitano del llamado "Estado local") (Saunders, 1981; 1986). Sólo años después fueron aproximándose dichas teorías a las de los MS en general. En cualquier caso, la sociología urbana bajo ese signo comenzó a incluir entre sus objetos de investigación fenómenos tan dispares como la planificación urbana, la reestructuración económica de las metrópolis, la apropiación cultural de los espacios, la relación entre procesos de inversión productiva y de reproducción de la fuerza de trabajo, etc. Como resulta evidente, esa concepción de lo urbano como ámbito exclusivo del consumo colectivo (y más aún si se reducía únicamente a la 
R I S

REVISTA INTERNACIONAL DE SOCIOLOCIA

No 34, Enero-Abril, 2003

MIGUEL MARTINNEZ LÓPEZ

"gestión" de los servicios sociales proporcionados por la administración local y de los equipamientos urbanos en que se ubicarían espacialmente) no aseguraba que los MSU o las luchas puntuales en interacción con las políticas urbanas, fueran centrales en la teoría o que se relacionasen con otros MS.

No fue precisamente esa pérdida de centralidad de los MSU lo que se podía encontrar en la obra de Castells hasta mediados de los años ' 80 . Al contrario, ese autor sugería análisis globales de esas dinámicas urbanas (locales) en las que los MSU constituían, incluso con valoraciones en exceso optimistas, fuerzas centrales del cambio social. Pero, como veremos después, tampoco podemos aceptar el "particularismo" analítico dentro del ámbito urbano al que frecuentemente se les redujo. De hecho, un importante punto de desacuerdo se abrió en el momento en que se trataron de establecer las referencias empíricas diversas que comprendía la noción de MSU y la concepción del cambio social que se hallaba latente en el debate acerca de la centralidad o no de los MSU.

Por una parte, no precisa mayor aclaración la tesis de que no pueden ser MSU, desde las premisas básicas de la sociología urbana neomarxista, todos aquellos MS que tengan en las ciudades sus sedes organizativas, sus focos de protesta $o$ el origen social de sus activistas. Pero el anterior aserto no obsta para que no se puedan considerar las dimensiones urbanas de algunos MS que actúan en ámbitos del consumo colectivo (sería el caso, por ejemplo, de la creación de cooperativas de viviendas por algunos sindicatos, o de la defensa de espacios donde alojarse $o$ donde reunir a los medios de comunicación, alternativa que promueve el movimiento antiglobalización). Es más, en numerosas ocasiones se hace difícil trazar una línea de separación entre los MSU "clásicos" y otros, como el ecologista y el feminista, desde los que a menudo se incide abiertamente en aspectos de la reproducción social y económica del espacio (cuidado familiar, servicios sociales de atención especializada, calidad de los alimentos, gestión de los residuos, etc.).

En todo caso, se han considerado como MSU "clásicos" casi todas las luchas de barrios por la provisión de vivienda social o de equipamientos públicos (escolares y hospitalarios, fundamentalmente), las protestas de inquilinos ante planes de renovación urbana, las organizaciones de propietarios frente a infraestructuras públicas o frente a la instalación de industrias en su vecindad, los conflictos con minorías étnicas, las acciones de ocupación de terrenos o de viviendas vacías, las movilizaciones ecologistas (ante la contaminación, el gasto energético, la gestión del transporte público, etc.) y, sobre todo, las actividades reivindicativas en el urbanismo y la apropiación sociocultural del espacio que protagonizan, destacadamente, las asociaciones vecinales. Para que a todas estas manifestaciones les podamos atribuir el carácter de MS, no obstante, debería tratarse de acciones colectivas que trasciendan, en alguna medida, los problemas particulares y localistas: es decir, que apunten a problemas urbanos comunes a ciudades de un mismo Estado (o de varios) y que esas dinámicas de acción colectiva se comuniquen de alguna forma significativa entre sí, con una mínima coincidencia en un mismo 
ciclo histórico, en acontecimientos semejantes del contexto social con los que se relacionan y con predominio estratégico de vías no institucionales de acción (Martínez, 2002).

Por lo tanto, no es posible tratar como MSU a cualquier demanda asociativa o a cualquier campaña de protesta en el ámbito reproductivo si no se observa una regularidad del mismo colectivo o la inserción de esas acciones en tendencias más amplias en la misma o en otras ciudades y áreas metropolitanas. Pero es conveniente notar que esos vínculos entre lo local y lo global son, a menudo, el objeto mismo a dilucidar por la investigación. Además, resultaría más fructífero elaborar una exhaustiva tipología de distintos MSU y una buena teoría holística sobre la sociedad en sus dimensiones estructurales e históricas para adoptar la necesaria distancia evaluativa que distinga acciones colectivas singulares ("grupos de presión", simples campañas de voluntariado, etc.) de MS más amplios (no necesariamente de "masas", pues, ni tampoco necesariamente "proactivos" o "progresistas").

Por otra parte, al tiempo que estamos poniendo de relieve la utilidad analítica proporcionada por las nociones más básicas de la sociología urbana neomarxista, no podemos dejar de lado nuestro desacuerdo con parte de esa escuela para la que los MSU habrían pasado de un exagerado auge a un casi irrelevante declive. En ese sentido, las más recientes obras de Castells representarían una confirmación de esa caída, cuando no reconfiguración de los MSU mediante nuevas alianzas con los gobiernos municipales ante los retos de la "globalización" (Borja y Castells, 1997). Esa línea de análisis ha dado lugar, por lo tanto, a una perspectiva en la que cualquier acción colectiva antes considerada como parte de un MSU, es ahora concebida tan sólo con relación a las políticas urbanas locales, acentuando el carácter coyuntural de éstas y sus restricciones institucionales (competencias, recursos, fiscalidad, etc., legalmente asignados). Parecería, en conclusión, que no existen ya MSU que se salgan de los límites localistas (con integración institucional y con fuerte dependencia del sistema de partidos y de élites parroquiales) y que se adhieran a objetivos más globales de cambio social. Ya no desafiarían frontalmente, en el dominio reproductivo, los efectos de desigualdad generados por el capitalismo, sino que pasarían a ser considerados mayoritariamente como unas "perturbaciones" más de la vida local y nacional con las que deben contar los gobiernos, aprovechándose éstos, además, de la decreciente fuerza e impacto público de aquéllos.

Más bien, lo que defiendo aquí es que ni tan "revolucionario" era antes el papel de los MSU, ni tan "conservador" es ahora. Pero no es esa, a mi entender, la cuestión esencial. El hecho de "descubrir" MSU en la actualidad o en el futuro nos exige, en todo caso, que poseamos un marco teórico en el que entender su casuística, sus dimensiones, sus efectos y sus contextos relevantes. Se trata, por tanto, de analizar los procesos sociales que protagonizan distintos grupos sociales en tanto que parte de un MS (activistas, simpatizantes, colaboradores, afectados, 
RIS

REVISTA INTERNACIONAL DE SOCIOLOGIA

№ 34, Enero-Abril, 2003

MIGUEL MARTINEZ LÓPEZ

etc.: Pakulski, 1991) y el "significado urbano" de esas luchas dentro de dinámicas amplias que pueden llegar a oponerse al orden político y capitalista, especialmente en sus momentos de reestructuración (Pickvance y Preteceille, 1991; Harvey, 1996). Expresado en otros términos, precisamos conocer la estructura de todas las mencionadas luchas urbanas que coexisten actualmente (su regularidad, extensión, lo que tienen en común, etc.) y su interacción con las políticas urbanas (en el nivel institucional, en las dinámicas locales del capital, en las relaciones de poder comunitarias, etc.), tanto como sus condiciones sociales de posibilidad y sus efectos de largo alcance en múltiples dimensiones de la realidad social. Una estrategia como la pergeñada en este punto, pues, es la que consideramos ausente en la evolución teórica de Castells aunque se puedan encontrar en su obra algunas indicaciones para seguir por este camino y así lo han hecho algunos autores (Dunleavy, 1982; Fainstein y Fainstein, 1993; Mayer, 1993).

\section{LOS MSU SEGÚN CASTELLS: ENTRE EL CONFLICTO POR EL VALOR DE USO Y LA REACCIÓN IDENTITARIA}

Para Castells, inicialmente, los MSU eran la contrapartida directa de la planificación urbana y eran evaluados por sus efectos de transformación social. La política urbana estaba compuesta, principalmente, por esas dos prácticas. La planificación urbana en general (el "urbanismo" o el "planeamiento urbano", podríamos decir de forma equivalente) consistiría así en la intervención política en "lo urbano", es decir, en el ámbito de la reproducción de la fuerza de trabajo, «regulando las contradicciones no antagónicas y reprimiendo las antagónicas, asegurando la realización de los intereses de la clase dominante» (Castells, 1972: 312). Los MSU serían las prácticas que tenderían «objetivamente hacia la transformación estructural del sistema urbano o hacia una modificación sustancial de la relación de fuerzas en la lucha de clases, es decir, en última instancia, en el poder del Estado» (ibid.).

Con relación a sus efectos, sin embargo, no toda práctica política de oposición social a la planificación urbana terminaba en la transformación de la «ley estructural del sistema urbano» (Castells, 1972: 317), por lo que sólo para estos casos reservaba la calificación de MSU; mientras que para el caso en que los efectos eran de regulación (o control o «reproducción del sistema urbano») y de reforma («modificación de un elemento del sistema urbano») reservaba las etiquetas de "participación" y "protesta", respectivamente.

¿Cómo llegaba un MSU a provocar efectos urbanos de largo alcance, que afectaran al corazón de las relaciones sociales capitalistas de dominación y a su manifestación en el sistema urbano? Según Castells, gracias a la unión de los MSU con los partidos políticos de izquierda y con los sindicatos, puesto que junto a ellos podrían acumularse las contradicciones del sistema, sobre todo las políti- 
cas y económicas: «cuanto mayor es el número de contradicciones acumuladas, mayor es su carga social, potencialmente movilizadora. Cuanto más situadas en lo económico son las contradicciones, o derivadas de contradicciones en esta instancia, mayor es su importancia. Contrariamente, cuanto más puramente políticas o ideológicas, más integrables resultan en una regulación del sistema» (Castells, 1972: 321). Según este autor, pues, si la acción colectiva sólo tiene efectos «puramente urbanos», sin encadenar entre sí la totalidad de contradicciones sociales, entonces nunca podría constituirse un MSU, sino únicamente una organización de reforma, de participación y de protesta.

El caso de Chile hasta el 11-S de 1973 - con sus movimientos de ocupación de tierras, la autoconstrucción de viviendas, la autoorganización comunitaria de la comida y la relación de los dirigenes vecinales con el Frente Popular que llevó al gobierno a Allende - servía de ejemplo histórico para caracterizar el éxito y prototipo de MSU que alcanzó esos niveles. Los fracasos de las luchas urbanas en París también a finales de los años ' 60 y principios de los '70 eran valorados con el mismo baremo. Sin embargo, posteriores análisis del movimiento gay en San Francisco o del movimiento ciudadano en Madrid durante toda la década de los ' 70 , entre otras referencias internacionales que tuvo en cuenta, condujeron a Castells (1983) a concepciones bien distintas sobre los MSU.

Ahora reconocerá que los MSU ya no tienen un papel protagonista en el cambio social dentro de las sociedades capitalistas o, por lo menos, que tienen unas funciones más específicas y restringidas dentro de éste. Esa restricción estará en lo propiamente "urbano" y no exigirá que los MSU se alíen necesariamente con los partidos políticos o con los sindicatos de clase. Más bien, el éxito de los MSU se medirá ahora por su eficacia en transformar el "significado urbano" y no todo el sistema urbano. Eso se conseguiría, precisamente, con una fuerte autonomía con respecto a los partidos políticos, aunque manteniendo relaciones mutuas siempre que cada parte respete el ámbito propio de acción de la contraparte. Los partidos, pues, tendrían su parcela legitima en la política urbana en los sistemas democráticos, y no deberían ser observados como parte de un "frente popular" ante la planificación urbana.

Los MSU empiezan a ser vistos como esencialmente "reactivos" y como "comunidades" fundamentalmente impotentes ante un contexto económico global, aunque la transformación urbana que podrían alcanzar implicaría, sobre todo, a formas de autogestión y de control vecinal de sus territorios más próximos. Esa transformación, de todos modos, conseguiría cambios sociales más allá de los pequeños efectos locales cuando dichos MSU se aliaran con otros MS más centrales en la nueva etapa del capitalismo postindustrial (aludiendo aquí Castells al caso del feminismo).

Para Castells, sólo el movimiento ciudadano madrileño habría conseguido una transformación global del significado urbano. Mientras que el resto de movimientos analizados sólo habrían conseguido incidir en algunos aspectos o dimensiones 
parciales del mismo. Pero, ¿qué se quiere decir con "significado urbano"?

En primer lugar, entiende por "significado urbano" «la realización estructural asignada como objetivo a las ciudades en general (y a una ciudad en particular en la división interurbana del trabajo) por el proceso conflictivo entre los actores históricos de una sociedad dada» (Castells, 1983: 406). Aunque también se produzcan conflictos sociales en las áreas de la planificación de las funciones urbanas o en las del diseño de la forma urbana, el cambio social sería, para este autor, fundamentalmente una cuestión de redefinición del significado urbano: es decir, de las funciones globales que cada espacio cumple para la reproducción del capitalismo. Los MSU, pues, «imponen un nuevo significado urbano en contradicción con el significado urbano institucionalizado y contra los intereses de la clase dominante» (Castells, 1983: 409).

En el caso de Madrid, esa redefinición de lo urbano que consiguió el movimiento ciudadano abarcaba reivindicaciones como la vivienda, la enseñanza, la salud pública, el transporte, los espacios libres, la preservación del casco histórico, la promoción de la vida cultural y asociativa, y demandas de participación política (Castells, 1983: 313-314). Sin embargo, ese conjunto podría agruparse estructuralmente en tres dimensiones más básicas: la orientación hacia el consumo colectivo (servicios urbanos con valor de uso), la organización asociativa y cultural de la vida comunitaria, y la búsqueda de la descentralización política y de la autogestión vecinal:

1) «Lograr para los residentes, una ciudad organizada en torno a su valor de uso (...) En cualquier lugar donde se produjo la movilización, ésta iba dirigida a la mejora del consumo colectivo, lo que estaba en contradicción con el concepto de ciudad destinada al provecho, donde la deseabilidad del espacio y de los servicios urbanos se distribuye de acuerdo con los niveles de ingresos.»

2) «La búsqueda de la identidad cultural, del mantenimiento o la creación de culturas locales autónomas, étnicamente basadas o históricamente originadas. En otras palabras, la defensa de la comunicación entre las gentes, el significado social definido de manera autónoma y la interacción personal contra el monopolio de los mensajes por los medios de comunicación (...). Al movimiento orientado hacia este objetivo lo llamamos comunidad.»

3) «La búsqueda de un poder creciente para el gobierno local, la descentralización de los barrios y la autogestión urbana, en contradicción con el Estado centralizado y una administración territorial subrodinada e indiferenciada.» (Castells, 1983: 430-431).

Las dos últimas dimensiones, por lo tanto, se añaden ahora como aspectos nuevos de lo propiamente urbano. A cambio, el conjunto de las prácticas 
sociales de los MSU pierde trascendencia política en el resto de la ciudad y del sistema social y económico: ya no necesitaría transformar esas macrocontradicciones para ser un MS, serían suficientes las "reformas" en los ámbitos urbanos sublocales, siempre que fuesen "integrales" en el sentido de articular esas tres dimensiones.

En segundo lugar, Castells concluye que las luchas urbanas tendrían una entidad propia y que no serían reducibles a las luchas de clases, étnicas o de género, aunque podrían solaparse con éstas. Lo esencial de los MSU sería la diversidad de miembros y simpatizantes que reúnen. Tendrían una «base multiclasista». Los datos recogidos, además, le permitían verificar que las clases medias no eran el componente mayoritario de las asociaciones vecinales de esa época, y sólo en algunos barrios era significativa la constante autoconciencia como clase obrera para el éxito de las reivindicaciones (Castells, 1983: 362, 431):

«Cada movilización de barrio solía estar basada en una clase, pero, en conjunto, el movimiento, en sus campañas de organización colectiva, ideología, imagen y colaboración para producir efectos urbanos, políticos y culturales, comprendía una pluralidad de clases sociales. En consecuencia, su adhesión de clase era una dimensión importante a la hora de definir cada movilización y de fomentar su dinámica en los barrios de clase trabajadora. (...) Los trabajadores y los barrios libraban batallas distintas, aun cuando se enfrentaban a menudo con la misma policía e intercambiaban mensajes de solidaridad inspirados por una matriz política común: eran aliados, no camaradas (...) Las reivindicaciones comprendían todos los aspectos de la vida menos el trabajo.» (Castells, 1983: 362-364).

Sin embargo, el protocolo metodológico seguido usaba las posiciones de clase y la conciencia de clase obrera de algunos barrios sólo como «variables de control» que permitían apuntalar los análisis referidos a las tres dimensiones básicas y a los efectos y éxitos conseguidos en cada dimensión. De forma complementaria, se establecían tres elementos «operadores» de conexión con el resto de la sociedad: uno con matices de clase (la participación de clases profesionales en casi todas las asociaciones estudiadas) y otros dos sin ellos (la relación con los medios de comunicación y la relación con los partidos políticos, siendo esta última la más acentuada en el estudio) (Castells, 1983: 377). Estos «operadores» (que podríamos reconceptualizar como «mecanismos de mediación» entre las acciones movilizadoras del movimiento y los contextos sociales más inmediatos: Koopmans, 1995) mejoraban sustancialmente el análisis sociológico pero parecían tomar el relevo, en importancia analítica, que antes tenían las alianzas de clase.

El tercer aspecto importante de ese estudio era el de los efectos obtenidos o provocados por esos movimientos. Por un lado, Castells rechazaba las explicaciones estructuralistas monocausales: el contexto histórico determinó las condiciones de posibilidad del movimiento, pero también éste fue modificando ese contexto de 
RIS

REVISTA INTERNACIONAL DE SOCIOLOGIA

№ 34 , Enero-Abril, 2003

MIGUEL MARTINEZ LÓPEZ

modo tal que se crearon unas nuevas «representaciones sociales» que van a condicionar de nuevo las oportunidades y el desarrollo posterior del movimiento.

«Se podría decir que Madrid cambió porque murió Franco y se estableció la democracia española. También cabe invertir el argumento: el Movimiento Ciudadano fue un factor decisivo para el establecimiento de la democracia. Propuso asimismo una nueva serie de objetivos urbanos sin el conocimiento y, a veces, a pesar de la hostilidad de los partidos de izquierda [...] Toda la política y la ideología urbanas fueron remodeladas en España por el Movimiento Ciudadano y de acuerdo con sus orientaciones. Y cuando en 1980-1981 quedó en gran parte desmantelado el Movimiento por la izquierda que había accedido al poder y quedaron paralizadas algunas grandes reformas urbanas, la izquierda entró en crisis» (Castells, 1983: 433).

En el ámbito del valor de uso del espacio urbano se habían conseguido remodelaciones de barrios de chabolas, rehabilitaciones de viviendas públicas, preservación del centro histórico y participación popular en los procesos de planificación urbana para frenar el acelerado y descontrolado desarrollo metropolitano. En el ámbito comunitario y cultural destacó, especialmente, la recuperación de las fiestas populares y la dinamización de actividades culturales en cada barrio, rompiendo tanto con su ausencia producto del aluvión migratorio que arrastraba a poblaciones con desarraigo espacial, como con la censura impuesta por el propio régimen político dictatorial. En el ámbito político se promovieron derechos de asociación, exigencias de descentralización administrativa y gran parte de los temas que enarbolarían después los partidos políticos en sus programas electorales (Castells, 1983: 351-357).

A partir de estas novedades conceptuales y de los ejemplos empíricos ofrecidos, Castells sugería que el caso madrileño podía servir como modelo para el resto de MSU en relación con los cambios sociales "exclusivamente urbanos" que podían obtenerse. Al mismo tiempo, su interpretación del ciclo histórico de protestas urbanas era que, lejos de declinar, por todo el mundo seguían apareciendo MSU que iban tomándose el relevo mutuamente y que la crisis urbana seguía «viva y coleando». Ahora bien, los MSU ya no eran considerados como fuerzas revolucionarias, sino casi todo lo contrario: sólo alcanzarían a influir en sus gobiernos locales, pero no en el ámbito estatal, y mucho menos en relación con los «imperios mundiales [de las empresas transnacionales] y las burocracias computerizadas» (Castells, 1983: 444). Por esa razón usará ahora indistintamente la terminología de MSU, movimientos urbanos y comunidades locales.

En su más reciente y celebrada publicación (Castells, 1997), este autor reconoce la multiplicidad de MS observados mundialmente en la última década, pero reserva su valoración como proactivos sólo a algunas modalidades de feminismo y ecologismo. Los MSU siguen siendo analizados como expresiones 
reactivas, defensivas o conservadoras. Estarían muy limitados localmente ante la globalización económica, basada ésta, entre otras cosas, en las tecnologías de la información y en la hegemonía de flujos financieros internacionales al margen de cualquier control ciudadano o estatal. La misma caracterización, aunque con estudios de caso a veces muy simplistas, atribuye a las luchas étnicas, a los movimientos nacionalistas o a los fundamentalismos religiosos. En gran medida, pues, consolidaría su última línea interpretativa, y las potencialidades de autogestión política (la tercera dimensión de su esquema anterior) de los MSU se diluirían irremediablemente en las dinámicas de un capitalismo cada vez más compuesto de flujos y redes transnacionales.

Se constataría ahora que ningún MS habría conseguido la centralidad en su oposición al capitalismo, ni tampoco se habría producido la esperada unión con los MSU. Éstos, por lo tanto, habrían continuado su repliegue localista casi a lo largo del mundo entero, según Castells. En concreto, este autor señala que durante los años ' 80 y ' 90 predominaron cuatro tendencias: 1) la integración de los MSU en los gobiernos locales; 2) su integración en el movimiento ambiental, sobre todo, en los aspectos localistas y menos globales (las protestas tipo NIMBY: «en mi patio trasero, no»); 3) la organización de la «supervivencia colectiva» en barrios pobres de muchas ciudades y metrópolis del mundo (en forma de Estados del Bienestar alternativos); 4) el control espacial y económico de los barrios por bandas juveniles (Castells, 1997: 83-87).

Por último, la terminología que se adopta finalmente es ya sólo la de "movimientos urbanos" o "comunidades locales". Y de las tres dimensiones del anterior análisis "estructural", será la identitaria o cultural la que gozará ahora de mayor poder explicativo de estas organizaciones urbanas. «Así pues, las comunidades locales, construidas mediante la acción colectiva y conservadas mediante la memoria colectiva, son fuentes específicas de identidades. Pero estas identidades, en la mayoría de los casos, son reacciones defensivas contra las imposiciones del desorden global y el cambio de ritmo rápido e incontrolable. Se construyen refugios, sí, pero no paraísos» (Castells, 1997: 88).

\section{LAS OLVIDADAS CRÍTICAS A CASTELLS: LOS PROBLEMAS DE LA AUTONOMÍA Y LOS EFECTOS DE LOS MSU}

Es difícil desligar el debate sobre la concepción sociológica que forja Castells, de los fenómenos específicamente urbanos y de los MSU entre ellos. Intentaremos ceñirnos aquí a discutir el estatuto de estos últimos, aunque resultará evidente que de ello se derivará también una exigencia de revisión teórica de lo que entendemos por "lo urbano". De hecho, la primera polémica que se puede reseñar es la que aparecía ya explícita en las primeras y duras críticas de Castells a Lefebvre. Aunque otros autores buscaron algunos puntos de equilibrio entre ambas posiciones, lo que 
RIS

REVISTA INTERNACIONAL DE SOCIOLOCIA

№34, Enero-Abril, 2003

MIGUEL MARTINEZZ LÓPEZ

parece comprobarse, a la luz de lo expuesto en el punto anterior, es que Castells le fue dando parte de razón a Lefebvre, reconociendo la relativa "autonomía" de las luchas urbanas y la relativa "centralidad" de sus dimensiones identitarias. En mi opinión, sin embargo, no ha sido esa la mejor solución, sino que me parecen más útiles tanto los puntos de compromiso entre ambos, como buena parte del modelo de articulación integral propuesto en La ciudad y las masas. Veámoslo con un poco más de detalle.

Castells (1972: 107-117) le criticaba a Lefebvre $(1968,1970)$ el carácter "ideológico" de su sociología urbana, el predominio de la sucesión histórica de "modos de pensamiento, de acción y de vida" sobre la sucesión de "modos de producción", el haber considerado las luchas urbanas como más centrales incluso que las luchas de clase (debido a que el capitalismo habría evolucionado hacia una "sociedad urbana" atenuando muchas de sus principales contradicciones) y el concebir el espacio como producto de la actividad creadora de los seres humanos, de sus proyectos, de sus modos de habitar y de sus relaciones en la vida cotidiana, en mayor medida que como producto de las determinaciones abstractas (generales) del sistema capitalista. En el fondo, a mi parecer, no se trataba de dos visiones mutuamente excluyentes, aunque la perspectiva más dialéctica y accionalista de Lefebvre indicaba, sobre todo, que la urbanización del espacio tenía un origen anterior al capitalismo y su valor de uso habría que buscarlo, por lo tanto, en las formas de organización comunitaria, en la vida cotidiana, y en las prácticas de "habitar" y de "apropiación" material y cultural del espacio. Tales fenómenos ampliarían, en consecuencia, el ámbito de lo urbano y de la intervención del Estado que en Castells parecía restringido al "Estado de bienestar" (aunque es justo notar que en el "sistema urbano" de Castells los procesos de reproducción de la fuerza de trabajo y la gestión política local articularían social y espacialmente todos los procesos económicos mediante la planificación urbana).

La principal diferencia entre ambos autores estribaba en que para Castells existiría un único actor (el proletariado) que participaría en dos luchas de clase (por el salario directo y por el salario indirecto) frente a dos enemigos (el capitalista y el gobernante del Estado), mientras que para Lefebvre podía haber múltiples actores participando en luchas específicamente urbanas (por la creación de espacios libres y autogobernados) y el enemigo sería principalmente el Estado en tanto que garante de los fundamentos mismos de todo el sistema capitalista (la propiedad privada y las relaciones sociales basadas en el valor de cambio), y no sólo como planificador urbano o gestor de políticas públicas (Gottdiener, 1984). Por lo ya expuesto antes, no es difícil percatarnos de la convergencia del segundo Castells con esas ideas de Lefebvre.

Pero también es conveniente anotar que a este último se le ha criticado, aún desde planteamientos afines, el "optimismo revolucionario" que deposita en los MS basados en la conquista del espacio urbano (Harvey, 1973: cap. 5-6, 318-330) y la carencia de una teoría sobre la dependencia del urbanismo en general (inclu- 
yendo las acciones de los MSU) con respecto a dinámicas más amplias del capital en el ámbito de lo "productivo" y de lo "mercantil" (la localización industrial, las inversiones en capital fijo, la especulación con los derechos de propiedad, la creación de nuevas necesidades y demandas en el consumo, etc.), también ausente en las primeras contribuciones de Castells (posteriores trabajos de Harvey, sin embargo, sí serán integrados por Castells en parte de su interpretación sobre la evolución postfordista del capitalismo global).

Un segundo punto de polémica ha sido el énfasis de Castells en analizar los MSU a partir de sus efectos. En primer lugar, esa perspectiva le obligaba a considerar sólo los procesos sociales en los que se producían "grandes cambios estructurales", como si otras formas de participación urbana no produjeran cambios "significativos" y como si los extraordinarios casos de "auténticos" MSU pusieran tan alto el listón que todas las demás formas de MSU y "participación urbana" sólo fueran una imagen distorsionada de lo que podían llegar a ser. Esto se traducía inicialmente en que los MSU se dedicaban a la revolución y otras organizaciones sociales de ámbito urbano a la participación y/o la reforma. Muchos investigadores, sin embargo, rechazaron las mencionadas implicaciones de esa categorización y, desde el extremo opuesto, calificaron como MSU o simplemente como movimientos urbanos a todo tipo de organizaciones urbanas, protestas y actividades comunitarias, independientemente de la escala o la intensidad de los efectos que producían, ya que, de lo contrario, razonaban, era fácil quedarse sin objeto de estudio (a no ser que la mayoría de casos fueran MSU sólo "por defecto") (Fainstein y Hirst, 1995). En todo caso, seguiría pendiente en esa crítica el comprobar que tales luchas urbanas constituyen MS porque son reiteradas en el tiempo o en el espacio, porque hay políticas locales o estatales que concentran una oposición común en varios lugares y con varias formas de protesta dentro de repertorios afines, etc.

Pickvance $(1975,1985,1994)$ llega a una conclusión semejante y añade que el análisis de los efectos y, por lo tanto, del éxito de los MSU propuesto por Castells presentaba dos serios defectos más: 1) que no exigía analizar en el mismo orden de prioridad las organizaciones y recursos organizacionales de quien componía el movimiento - porque lo principal eran las contradicciones sociales enfocadas por el mismo-; y 2) que no consideraba los efectos derivados de la relación del movimiento con las autoridades estatales, ya que se privilegiaba el análisis exclusivo de la "fuerza social" de la movilización alcanzada por el movimiento.

Esas críticas me parecen válidas, pero dejan todavía otro problema que tampoco Castells trató: los efectos de las movilizaciones hacia el interior del movimiento. Es decir, el análisis de las relaciones internas entre los distintos colectivos (organizados o no) que constituyen el movimiento y la reproducción en su seno de estructuras de poder externas (Villasante, 1995). En gran medida, se trata de los efectos menos visibles y no mantienen una relación de necesidad con la eficacia en alcanzar los objetivos explícitos de los movimientos. 
RIS

REVISTA INTERNACIONAL DE SOCIOLOCIA

№ 34, Enero-Abril, 2003

MIGUEL MARTÍNEZ LÓPEZ

Además, la asunción de Castells acerca del carácter progresista de los MSU (ya sean proactivos, como los examinados al principio, o algunas de las experiencias comunitarias "reactivas" que señala después), le impediría prestar atención a los procesos de definición de la realidad desde el movimiento (sus proyectos, percepciones, valores, etc.) o desde fuera de él (su imagen pública), considerando el rango de connotaciones que tienen sus objetivos y la realidad que interpretan, las prioridades establecidas entre sus fines, la concepción y selección de los medios estratégicos de acción y los conflictos grupales o personales en su seno por imponer esas visiones de la realidad (Rivas, 1998). Lo urbano y los MSU, pues, no podrían ser ya ni una simple prolongación de los conflictos productivos, ni un modelo unificado y restringido del "significado urbano", sino lo que distintos agentes sociales (incluidos los variados miembros de los movimientos, sus aliados, sus enemigos, sus observadores, etc.) construyen a lo largố de un proceso continuo (aunque no infinito) de conflictos sociales y de intervenciones espaciales y materiales.

Posiblemente a consecuencia de críticas como éstas, en la segunda etapa teórica de Castells se incrementa la noción de lo urbano, a mi parecer de forma valiosa, aludiendo tanto a los procesos de consumo colectivo ( $\mathrm{y}$ de gestión política de ese consumo) como a las construcciones culturales del espacio y a la autoorganización política popular a escalas locales o barriales. Sin embargo, ¿no se habría perdido por el camino precisamente el vínculo más directo de los MSU con las contradicciones esenciales del sistema social? Es decir, ¿qué vínculos podemos considerar como hipótesis orientadoras de la investigación sobre los MSU, en su relación con las clases sociales, con la producción urbana guiada por los intereses de la acumulación capitalista y con la política urbana de cada ciudad? Para Castells, los MSU, en efecto, combinarían el "sindicalismo de consumo colectivo" con la comunicación y con el poder (Castells, 1983: 430-432), pero esa transversalidad sería limitada, porque sólo una parte del poder político estaría descentralizado en cada barrio y porque no se vincularían directamente con las luchas de clases, étnicas o de género. Por lo tanto, permanecerá en dicha concepción un hiato que tampoco se vislumbra superado en los últimos escritos.

Como respuesta a ese problema, una opción posible consiste en revisar la taxonomía que se derivaba de los tres vectores del "significado urbano" cuando se generaban MSU sectoriales. Pickvance (1985), por ejemplo, propuso una clasificación más específica. En relación con el consumo colectivo, distinguió entre movimientos para la provisión de vivienda y servicios urbanos (cuando no existen), y movimientos para acceder a ellos (cuando existen, pero no se usan o hay desacuerdo con las reglas institucionales en las que se basa su gestión). En relación con los procesos políticos, habría movimientos dirigidos a conseguir el control y la gestión de la vivienda y de los servicios urbanos, así como de las instituciones políticas (no sólo el gobierno municipal en general, sino los procesos de planificación o de recaudación de impuestos en particular). En una visión 
más materialista de la dimensión comunitaria, que se podría denominar como de "proximidad espacial", estarían los movimientos defensivos ante amenazas físicas a la vecindad, como demoliciones, renovaciones urbanas o planes de desarrollo que implican construcciones de industrias, centros comerciales o carreteras; 0 ante amenazas socialmente percibidas, como la instalación en un barrio de familias pobres, de una minoría étnica, de un grupo social marginado, etc.

Avanzando sobre la tipología de Castells, el nivel del consumo colectivo distinguiría ahora entre demandas de bienes y servicios que no existen y demandas por el uso de esos bienes y servicios, cuando existen pero son administrados de forma no equitativa; el nivel político no implicaría sólo los niveles locales, sino también los de ámbito mayor (regionales, estatales o interestatales); y el nivel comunitario, a menudo valorado como "defensivo" o "reactivo", incluiría acciones ante amenazas fisicas de la reestructuración capitalista y conflictos culturales que pueden tener un signo progresista en la apropiación del espacio, tanto como un carácter exclusivista y discriminatorio.

El debate entre ambos autores (Castells, 1985; Pickvance, 1986) puso de manifiesto que hay algunas semejanzas estructurales básicas, pero Pickvance separa la centralidad del Estado en cada movimiento y no presupone la homogeneidad y el progresismo transformador de los MSU, mientras que Castells enfatizaría algunos de los aspectos de creatividad cultural y de autobogierno político de las comunidades urbanas. A pesar de sus virtudes analíticas y complementariedad, permanecen, a mi entender, problemas de fondo en ambas tipologías: ¿no son, acaso, los problemas urbanos así enfocados también de la incumbencia de otros MS no exclusivamente urbanos como el feminismo o el ecologismo?, ¿no se fijan sólo en los efectos visibles de los movimientos y no en los orígenes sociales de sus componentes ni en sus proyecciones ideológicas (Lowe, 1986)?, ¿no hay, acaso, en todos los niveles de la tipología un debate permanente entre acción y conocimiento, entre la población y la planificación, y entre formas de concebir la realidad urbana que se pretende apropiar y transformar socialmente (Villasante, 1995)?

Creo, en este sentido, que convendría más una distinción entre MSU sectoriales (como los referidos en lo económico, lo cultural o lo político, cuando no intentan una completa articulación entre esas dimensiones), MSU globales (donde encajarían algunas de las demandas feministas o de la ecología urbana, además de aquellos que articulen alternativas integrales en las tres dimensiones), MSU de colectividades "afectadas" (algunos de los defensivos y conservacionistas, pero también aquellos sectoriales que limitan su movilización a resolver su propio problema de vivienda asequible, por ejemplo) y MSU "alternativos" (que tendrían una proyección global, pero prácticas locales muy rupturistas con las instituciones, como las apropiaciones festivas y anticapitalistas de las calles de Reclaim the Streets - McKay, 1998- o la okupación de viviendas y centros sociales contraculturales). Pero, como se verá a continuación, quedan pendientes algunos parámetros teóricos relevantes para entender de forma holística los MSU. 
RIS

REVISTA INTERNACIONAL DE SOCIOLOGIA

№ 34, Enero-Abril, 2003

MICUEL MARTÍNEZ LÓPEZ

En conclusión, las polémicas cuestiones hasta ahora presentadas nos indican la necesidad de precisar la articulación entre los distintos tipos de movimientos urbanos y las distintas dimensiones de lo urbano que implican, a la vez que se debe examinar el alcance transversal de sus efectos, hacia fuera y hacia dentro de los propios movimientos. No hay por qué presuponer el carácter progresista de los movimientos, pero tampoco se deberían reducir los MSU a simples organizaciones comunitarias más o menos aisladas, si es que asumimos que todo movimiento precisa una cierta persistencia en el tiempo, una mínima coordinación o intercambio entre las organizaciones que lo componen o réplicas de organizaciones y movilizaciones en varios lugares de una ciudad o en varias ciudades al mismo tiempo. No es un criterio suficiente, pues, el hecho de que se consigan amplios efectos visibles de transformación social del capitalismo, aunque sí es necesario evaluar en qué medida formulan demandas que cuestionan la dominante organización urbana o del espacio en general (Mayer, 1993) o la refuerzan (como los movimientos conservadores de clases medias norteamericanas que se negaron a pagar impuestos en los '80: Fainstein y Hirst, 1995).

\section{LOS CONTEXTOS EXPLICATIVOS Y LAS RELACIONES INTERNAS DE LOS MSU}

Un tercer problema presente en las investigaciones de Castells es el referente a los aspectos contextuales de los MSU. En concreto, la cuestión no es que esos aspectos estén ausentes de sus estudios, sino que los usa de un modo exclusivamente contextual, es decir, como parte del contorno en el que actúan los movimientos, centrando el análisis en éstos y no en las relaciones entre ambos. Una consecuencia de esa concepción es que acaba considerando unas pautas generales de los MSU a partir del caso del Movimiento Ciudadano de Madrid, cuando algunos aspectos contextuales de este caso son dificiles de encontrar en otros (como la ilegalidad de los partidos políticos en un régimen dictatorial, por ejemplo). Se decide ahora Castells por una teorización de rango medio en la que no espera encontrar leyes generales de funcionamiento de los MSU ni del sistema urbano independientemente de cada contexto (político, económico y cultural, sobre todo). Sin embargo, en esa segunda etapa de sus estudios no dudó en observar un constante crecimiento de los MSU en amplias zonas del mundo, sin prestar la suficiente atención a las particulares relaciones contextuales de cada indicio, aparentemente en contra de sus propios postulados teóricos.

Pickvance $(1985,1986)$ orienta la parte fuerte de su crítica a Castells hacia ese punto. En concreto, le cuestiona que sólo tenga en cuenta aspectos contextuales cuando tienen efectos directos en los movimientos y sugiere, en consecuencia, que el énfasis analítico se sitúe en observar las relaciones entre los movimientos y los aspectos contextuales que se consideren relevantes para entender el conjunto 
de procesos sociales implicados, independientemente de que dichos aspectos contextuales tengan efectos visibles sobre el movimiento. Para Pickvance, podrían identificarse, por lo menos, cinco dimensiones contextuales relevantes con relación a los MSU: 1) los periodos de rápida urbanización que conllevan carencias urbanas de vivienda o servicios públicos; 2) la acción tolerante o intolerante del Estado hacia los movimientos, y su intervención en materias de consumo colectivo; 3 ) el contexto político en la medida en que existan movilizaciones políticas más amplias que las de los movimientos, el tipo de ideologías de clase o según otros parámetros que estén activos en la política urbana, y la efectividad institucional y de los partidos políticos para encauzar los conflictos sociales; 4) el desarrollo de las clases medias y de sus recursos en habilidades profesionales, contactos, tiempo, dinero y afiliaciones asociativas; 5) los aspectos económicos y sociales que favorecen u obstaculizan el desarrollo de los MSU, como el desempleo o los cambios culturales promovidos por otros MS (los juveniles o pacifistas, por ejemplo).

La virtud de ese modelo de análisis reside en la formulación de criterios de evaluación de la relación entre los movimientos y sus contextos significativos, por lo que la simple presencia de MSU o su crecimiento cuantitativo no significa que esos movimientos sean relevantes en su contexto. Un ejemplo de ello es el mantenimiento e incluso el crecimiento del movimiento vecinal en España en las dos últimas décadas, aunque su conflictividad urbana y su relación con otros MS hayan sido decrecientes (Alberich, 1993; Pastor, 1998). En esta última propuesta, a pesar de la advertencia teórica, parece continuar la insistencia en los "efectos visibles" de las relaciones entre los movimientos y sus contextos. Como se puede ver en el caso del movimiento de okupación, se pueden distinguir contextos relevantes para explicar el MSU como la "condición juvenil transitoria" o las limitadas competencias municipales en materia de vivienda, menos visibles que otros como la legislación específica (civil o penal) que afecta a esa práctica o las situaciones laborales y económicas de la población joven vinculada a ese movimiento (Martínez, 2002).

Por otra parte, el modelo de Pickvance parece integrar todas las críticas que le dirige Lowe (1986: 152-186) acerca de la necesidad de tener en cuenta la base social de los movimientos, las ideologías políticas a escala local y las relaciones de cooptación, marginación y represión ejercidas por el Estado o por empresas privadas. Pero Lowe también mantiene una crítica a toda tentativa exclusiva por modelizar los procesos sociales relevantes para la explicación de los MSU. Aparte de los problemas particulares que halla en los modelos de Castells y de Pickvance, Lowe considera que: 1) ningún modelo se refiere a las estructuras de poder urbanas que pueden marcar de forma oculta la agenda política y, por lo tanto, la no-acción de los movimientos; 2) no es posible decidir qué sociedades son las excepciones o la regla con respecto al modelo, y se dan variaciones dentro de cada país que pueden dar lugar a la coexistencia de distintos tipos de movimientos (por ejemplo, 
RIS

REVISTA INTERNACIONAL DE SOCIOLOCIÁ

№ 34, Enero-Abril, 2003

MIGUEL MARTÍNEZ LÓPEZ

movimientos por los derechos étnicos y por la exclusión racial al mismo tiempo: Fainstein y Hirst, 1995).

Por esas razones, Lowe propone una agenda de temas políticos y sociales que tienen una relación relevante con la movilización de los MSU, pero que, a grandes rasgos, no se diferencia mucho del conjunto de cuestiones enunciadas por Pickvance. Creo, en todo caso, que lo más importante de su contribución es el hacer explícitos los problemas de la evolución teórica de Castells no sólo con relación a sus limitados análisis contextuales, sino también con relación a las consecuencias que se derivan de ellos. En concreto, se argumenta, Castells esquivaría el problema de la relación entre los MSU y las nuevas situaciones laborales para la clase obrera, pasando a considerar una mayor autonomía de los MSU como una parte más de la esfera de la «sociedad civil». De ahí que sostenga que los MSU continuarían siendo una fuente de cambio social, pero difusa: es decir, que en realidad no podrían producir cambio social alguno por sí mismos, ya que en la esfera política (en el Estado) los partidos tendrían sus propias funciones, la policía y las empresas multinacionales ejercerían una dominación que ningún MSU puede eludir, y serían necesarios otros MS y «operadores organizacionales» (mass media y profesionales) para catalizar cambios desde las bases sociales (Lowe, 1986: 189-193). La ambigüedad residiría, por lo tanto, en que más autonomía conceptual de los MSU significaría más dependencia real de otros actores.

Otros analistas toman mayor distancia frente a esa posición de Castells y optan por indagar contextualmente en: la heterogeneidad de experiencias de MSU existentes, los vínculos reales con corrientes de nuevos MS como el pacifismo y el ecologismo en Alemania, el frecuente final de los MSU con la transformación de sus organizaciones y activistas en proveedores de servicios públicos, y la constante relación de los ciclos de protesta con las políticas económicas y cambios en los modelos de acumulación capitalista (Mayer, 1993). Ésta es también la perspectiva de Fanstein y Hirst (1995) quienes sugieren - a pesar de aceptar la mencionada posición dual de Castells- que un análisis comparativo de las relaciones entre movimientos y contextos puede hacerse también en base a efectos no visibles pero probablemente más explicativos que otros aparentemente más visibles (en cantidad de personas movilizadas o protestas realizadas, por ejemplo). De ese modo, enuncian las siguientes conclusiones (o "pautas de convergencia") de sus análisis de MSU, desde los años '60 hasta mediados de los ' 90 , en Europa y Norteamérica (aunque sería muy discutible su validez, por ejemplo, en las experiencias latinoamericanas: Friedmann, 1992; Villasante et al., 1994):

1) Los MSU pueden obtener impactos sustanciales en la política local o nacional, pero están severamente limitados por su incapacidad para mantener su movilización en el tiempo y sus objetivos programáticos sin caer en la "rutinización" o absorción por parte de la política institucional y de las políticas públicas de la Administración. Con frecuencia, en marcos de reestructuración económica, 
el propio Estado se encarga de adoptar las innovaciones de los MSU para suministrar servicios públicos.

2) El principal foco de tensión de los MSU se da en la relación con los gobiernos locales, y puede conducirles o bien a ser cooptados por éstos, o bien a carecer de los recursos básicos (públicos) para proseguir sus movilizaciones.

3) A pesar de las llamadas a las alianzas de clase o con otros MS, los MSU muestran una incapacidad sistemática para establecer coaliciones duraderas con otros colectivos, incluso con partidos políticos.

4) Aunque existe una amplia proclividad a que las clases medias protagonicen la mayoría de los MSU, existen también muchos basados fundamentalmente en identidades étnicas o según otras identificaciones (en relación con la vivienda, por ejemplo).

5) El nexo común de todo tipo de MSU, independientemente de su ideología o de otros aspectos, es una constante demanda de participación ciudadana en las tomas de decisiones municipales y en la gestión urbana local (cuyos ejemplos más evidentes serían los "presupuestos participativos") (Abers, 1998) o en su modalidad extrema, las propuestas del "municipalismo libertario" (Biehl y Bookchin, 1998), lo que se ha pretendido simular en muchas de las iniciativas municipales de promoción del voluntariado o en la llamada "planificación estratégica" (Martínez, 1999).

La última cuestión problemática de los análisis de Castells que quiero mencionar, no por puntual (con respecto al caso empírico del Movimiento Ciudadano de Madrid en la Transición) resulta a mi entender menos pertinente para señalar problemas teóricos de fondo. Se trataría de entender cómo en dicho estudio de caso no se aclararía suficientemente la composición de clase y organizativa del movimiento, su especificidad histórica y, sobre todo, sus dinámicas internas más relevantes, omitidas, en gran medida, en la metodología de análisis adoptada (a pesar, como hemos apuntado, de que se centraría más en el proceso de movilización que en las relaciones contextuales del movimiento).

Este autor señalaba, colateralmente, que las mayores capacidades movilizadoras se observaron en los barrios mayoritariamente obreros, aunque, de forma contradictoria, afirmaba que los MSU tenían predominantemente una base interclasista y que separaban claramente sus actividades urbanas de las más específicamente laborales o de clase (para mayor claridad sobre este punto, véanse sus intervenciones en la obra colectiva editada por Touraine, 1990). Más aún, la caracterización de la composición de ese movimiento como interclasista tampoco habría tenido en cuenta la diversidad de estilos y de comportamientos de las distintas organizaciones que integraban y dinamizaban el movimiento. Esos dos aspectos son los que sí pusieron de relieve otros analistas del mismo movimiento, desconocidos por muchos de los comentaristas internacionales de la obra de Castells (Villasante, 1984; Villasante et al., 1989). Desde estos planteamientos se sugería, por contra, que las cuestiones de clase social y de diversidad 
organizativa debían ser incluidas como dimensiones centrales de los MSU y no sólo como "variables de control". Por lo tanto, conviene detenerse un poco más en esas contribuciones alternativas que pueden ser de utilidad general para guiar sucesivos análisis.

Villasante sitúa primero los MSU en el contexto de toda su diversidad asociativa interna y externa, así como en una cierta continuidad con luchas reivindicativas más aisladas y concretas que tuvieron lugar incluso durante las primeras décadas del franquismo, precediendo a la explosión de los años sesenta. Esa explícita (aunque débil) continuidad histórica vendrá dada también, y podrá explicar el surgimiento del asociacionismo de los ' 60 y ' 70 , por acontecimientos y tendencias más globales, procedentes de otros países (corrientes cristianas progresistas, radicalismo de izquierdas distanciado de la Unión Soviética, visibilización de nuevos colectivos marginados a partir de mayo del ' $68 \mathrm{y}$, sobre todo, carencias básicas en los barrios periféricos de las áreas metropolitanas con rápido crecimiento inmigratorio) (Villasante, 1984: 92-97).

Para explicar las dinámicas sociales que permitieron la organización en cada barrio, este autor proponía atender no sólo a las reivindicaciones más manifiestas, sino a todas la relaciones de convivencia y vecindad en el plano "comunitario", de la vida cotidiana:

«La relación entre producción del espacio y movimientos sociales no es mecánica, sino que tiene como elemento de complejidad, y de una decisiva importancia, las tipologías de la vida cotidiana de las distintas vecindades. O sea, que la tipología del barrio, si sólo se considera desde la producción del espacio, nos lleva a la clave de las reivindicaciones y de los motivos de contradicción entre los usuarios y el sistema económico y político. Pero no nos aclara ni las formas ni los momentos, ni los agentes principales, que actúan como detonadores y mantenedores del conflicto. [...] Por ejemplo, Palomeras, donde la gente no sólo se autoconstruyó sus chabolas, sino que se ayudaron unos a otros durante veinte y tantos años, no sólo en la casa, sino en el agua, la luz, en todos los temas comunitarios, a la fuerza, la solidaridad fue algo muy natural. Y en un barrio además de casas bajas, de vida en las calles, de conocerse todos, de trabajar en la construcción un alto porcentaje (lo que implica relaciones en el barrio para saber de trabajos fijos o de chapuzas), etc., todo esto posibilita unos movimientos asamblearios y de contacto diario y hablado, muy diferentes de los conflictos de otros barrios, donde el desconocimiento entre vecinos es mayor, donde convocatorias con panfletos o carteles se hacen imprescindibles» (Villasante, 1984: 108-111).

Por otro lado, se concretaría la diversidad del Movimiento Ciudadano dando cuenta no tanto del interclasismo de sus miembros, como de los distintos papeles desempeñados en cada barrio por asociaciones no estrictamente vecinales, formando incluso "multimovimientos sociales": las Comisiones Obreras de barrios, las parroquias, 
las asociaciones deportivas y escolares, las cooperativas, los comerciantes, las escuelas de educación popular, etc. (Villasante, 1984: 111-113).

En tercer lugar, una línea de análisis de estos movimientos, igualmente preeminente, trataría de conocer la forma concreta que adoptan los conflictos, para lo cual se compondrá un esquema de redes de relaciones sociales cuyos elementos básicos (élites, grupos animadores, sectores activos, bases potenciales y procesos de comunicación con los respectivos "imaginarios" de cada colectivo) contextualizarían de forma más global el proceso de movilización del MSU. Con base en esas redes se podrían observar dinámicas sociales latentes como la impermeabilidad de la mayoría de asociaciones (los "grupos animadores" compuestos por activistas conscientes de los problemas generales) a la dominación por los partidos políticos, debido a que las estructuras de éstos eran suficientemente rígidas como para no poder imponer líderes locales y consignas demasiado sectarias, por lo menos hasta 1979 (Villasante, 1984: 115). Por otro lado, en el caso de los llamados "sectores activos" (a veces denominados "comunicadores informales" $y$ "colaboradores" con el movimiento) se llega a considerar que estos colectivos sociales, preocupados por luchas concretas más que por grandes ideologías o transformaciones sistémicas, serían las "claves de los conflictos" urbanos, puesto que estaban encargados de descentralizar la difusión y la movilización a ámbitos mínimos de la calle o de bloques de viviendas. Debido a su alta «movilidad, versatilidad y formas muy locales de aparecer y de organizarse», no sólo complementarían la labor de los grupos formales (las "organizaciones del movimiento", como se conocen en la literatura sobre MS: Tarrow, 1994), sino que serían los «comunicadores informales» quienes decidirían finalmente si la vecindad se moviliza o no (Villasante, 1984: 119).

Por último, para explicar lo que tenían de verdaderamente novedoso y el clima de euforia que representaron, Villasante proponía un análisis de los contenidos más latentes de los movimientos, más allá de sus reivindicaciones concretas sobre el consumo colectivo. A las dimensiones de la vida cotidiana y a las redes de relaciones entre distintos sectores en los barrios, habría que añadir el sentido global que tenían los proyectos de transformación social ínsitos en los movimientos: su horizonte político, sus alternativas de sociedad y de ciudad. La lucha contra la dictadura y la ruptura democrática promovida serían, según este análisis, los motores (o «analizadores») del movimiento, lo que lo cohesionará como tal, trascendiendo las luchas concretas.

«Siempre hubo movimientos ciudadanos por problemas concretos, pero lo peculiar de la etapa que va de finales de los años sesenta hasta finales de los setenta es que se abrieron posibilidades de experimentar desde los barrios unas luchas y unas movilizaciones que se entendían capaces de suponer una transformación radical de la ciudad. Esto animaba a los grupos, sin duda bastante politizados, que actuaban en los barrios, y a lo que hay que añadir que la perspectiva de la caída de la dictadura 
era un aliciente cercano en el tiempo para poner en marcha todas las formulaciones antimonopolistas y de organización popular en los barrios. (...) Las pretendidas exclusividades de los partidos políticos, de los ayuntamientos o de las asociaciones de vecinos nos parecen, a la luz de las experiencias analizadas, de una miopía excesiva. En la medida en que apareció un bloque solidario con ciertos objetivos comunes de ruptura democrática, fue posible el cambio y que cada movimiento consiguiera notable repercusión. Cuando desapareció la expectativa y el objetivo, y los protagonistas de unos y de otros se lanzaron a reclamar exclusividades para colocarse mejor en los procesos electorales, se perdió la meta unitaria y todo se disgregó» (Villasante, 1984: 131-132).

De hecho, los éxitos en materia de consumo urbano y descentralización administrativa fueron menos relevantes en relación con los éxitos políticos de legítimidad y de cambios en la cultura política obtenidos. Para esta interpretación, pues, las demandas en materia de consumo urbano o de apropiación cultural de los barrios estarían como mínimo atravesadas por el eje del horizonte político democrático y el modelo de ciudad alternativa.

Desde un punto de vista crítico, se puede objetar a este enfoque que no extraiga del material cualitativo que examinó más concreciones de las contradicciones internas de los movimientos sociales: las barreras para establecer alianzas prácticas (no sólo ideológicas) entre su diversidad asociativa y las limitaciones de los compromisos entre sectores dentro de los barrios y de las organizaciones (por ejemplo, la participación de profesionales acomodados sólo durante periodos muy eventuales, o las conductas paternalistas, dirigistas y ocultadoras de información que tienen muchas personas dirigentes con sus bases, en contra de su opción abiertamente declarada como asamblearia y antiautoritaria).

\section{CONCLUSIONES}

Mi propósito en este texto consistía en apuntar líneas teóricas de investigación de los MSU a partir de una revisión de las propuestas contenidas en parte de la obra de Castells. Esta tarea se ha abandonado relativamente en la última década, en buena medida debido a una frecuente desproblematización de las acciones de los MSU y, en otras ocasiones, debido a las dificultades por seguir considerándolos MS con semejante importancia a la atribuida a otros "nuevos" MS. Mi argumentación, sin embargo, parte de la persistencia de los MSU (clásicos y nuevos) y pretende demostrar que, a pesar de las evidentes virtudes analíticas que proporcionó parcialmente la sociología urbana de Castells, aún es manifiesta la carencia de un marco teórico holístico centrado en este particular tipo de MS.

Por una parte, se ha examinado la evolución conceptual de Castells en relación a los MSU percibiendo tres etapas: la primera, en la que aparecían como una 
fuerza de oposición a la planificación urbana y en la que se daba continuidad a la lucha de clases pero en el ámbito de lo reproductivo; la segunda, en la que se compuso un modelo estructural de análisis que añadía una dimensión cultural y otra política a las demandas sobre el valor de uso de la ciudad; la tercera, en la que se acentúan las concepciones comunitarias, identitarias y defensivas o reactivas de muchas de las luchas urbanas dificilmente consideradas ya como MSU.

A continuación se han identificado cuatro problemas teóricos en las contribuciones de Castells, sobre los que hasta ahora se habían formulado críticas sustantivas, pero rara vez se habían presentado de forma unificada. La primera de ellas se refiere a las dimensiones culturales, comunitarias y espaciales de las luchas urbanas con bastante independencia de las luchas de clase $y$, de hecho, con una composición social interclasista. El rechazo inicial de Castells a ese planteamiento es rectificado después, aunque se ha mostrado también que la autonomía de los MSU, proclamada ahora conceptualmente, se asentaba sobre un conjunto de dependencias reales de otros actores que dificultaba entender si finalmente eran o no fuentes importantes de cambio social. De hecho, hemos confrontado uno de sus principales estudios de caso con otra investigación que, precisamente, defendía a la vez el carácter clasista y comunitario del movimiento, pero destacando la relevancia de las relaciones internas formales (organizativas) e informales del movimiento.

Los otros dos problemas revisados se referían al análisis de los efectos y de los contextos de los movimientos. El énfasis inicial de Castells en analizar los MSU según sus efectos globales en las dinámicas capitalistas favorecía una cierta objetivación de su fuerza de cambio, a la vez que les daba un sentido más amplio a sus movilizaciones, más allá de sus demandas locales concretas. Pero comportaba el riesgo intrínseco de desvalorizar como MS a muchas luchas urbanas si no se percibían claramente dichos efectos y suscitaba una cuestionable clasificación de ellas cuando difícilmente podían articular todas las dimensiones sugeridas para transformar el "significado urbano". Además, los recursos organizacionales, la composición social, los efectos de cambio en el interior del movimiento o en sus ámbitos espaciales más próximos y en contextos sociales particulares, pasaban innecesariamente a un segundo plano de análisis. Del mismo modo, se ha argumentado que un análisis contextual más profundo que el defendido por Castells exigiría concretar los conflictos sociales tanto visibles (con influencia directa) como más invisibles (con influencia indirecta) que son relevantes para entender las relaciones de los movimientos con sus contextos. Aparte de las propuestas sobre la posibilidad de especificar qué contextos sociales son significativos para explicar los procesos sociales de los que son protagonistas los MSU, señalamos también otras dimensiones como la continuidad histórica de los movimientos, las relaciones con otros MS y los proyectos ideológicos que actúan como "motores" de muchas movilizaciones, además de los "mecanismos mediadores" entre los contextos y los movimientos que ya el propio Castells había tomado en consideración. 
RIS

En definitiva, creo que la obra de Castells ha ayudado a clarificar estas perspectivas teóricas en el estudio de los MSU, pero que, al mismo tiempo, se ha ido distanciando de este específico terreno de investigación precisamente por haber desatendido las dimensiones críticas señaladas. Tal vez sólo sea un síntoma de esa evolución el que cada vez ese autor observe menos MSU reales y las acciones colectivas urbanas que más se les asemejan tengan un carácter exclusivamente reactivo, localista 0 , incluso, reaccionario. Aunque esa selección empírica no sea lo más relevante a nuestros efectos, parecería que levanta algunas barreras innecesarias para estudiar tanto los viejos como los nuevos MSU y, sobre todo, para dotarnos de unas herramientas analíticas eficaces en el campo de las relaciones urbanas de poder.

\section{BIBLIOGRAFÍA}

ABERS, R. (1998), "From Clientelism to Cooperation: Local Government, Participatory Policy and Civic Organizing in Porto Alegre, Brasil”, Politics \& Society, vol.26, $\mathrm{n}^{\circ} 4$.

ALBERICH, T. (1993), "La crisis de los movimientos sociales y el asociacionismo de los años noventa", Documentación Social, $\mathrm{n}^{\circ} 90$.

BIEHL, J. y M. BOOKCHIN (1998), Las politicas de la ecología social. Municipalismo libertario, Bilbao, Virus-Los Arenalejos-Fund. Salvador Seguí.

BORJA, J. y M. CASTELLS (1997), Local y global. La gestión de las ciudades en la era de la información, Madrid, Taurus-U.N. for Human Settlements (Habitat).

CASTELLS, M. (1988 [1972]), La cuestión urbana, México, Siglo XXI.

(1986 [1986]), La ciudad y las masas. Sociologia de los movimientos sociales urbanos, Madrid, Alianza.

(1985), "Commentary on C.G.Pickvance's 'The Rise and Fall of Urban Social Movements", Environment and Planning D: Society and Space, vol.3.

(1999 [1999]), La era de la información: Economia, Sociedad y Cultura, vol.2: El poder de la identidad, Madrid, Alianza.

DUNLEAVY, P. (1982), "Perspectives on Urban Studies" en A.Blowers et al. (ed.), Urban Change and Conflict, London, Open University Press-Harper \& Row.

FAINSTEIN , N. y S.S. FAINSTEIN (1993), "Participation in New York and London: Community and Market under Capitalism", en R.Fisher, J.Kling (ed.) Mobilizing the Community. Local Politics in the Era of the Global City, California, Sage.

FAINSTEIN, S.S. y C. HIRST (1995), “Urban Social Movements”, en D. Judge et al. (ed.), Theories of Urban Politics, London, Sage. 
FRIEDMANN, J. (1992), Empowerment. The Politics of Alternative Development, Cambridge, Blackwell.

GOTTDIENER, M. (1984), "Debate on the Theory of Space: Toward an Urban Praxis", en P.Smith (ed.), Cities in Transformation. Class, Capital and the State, London, Sage.

HARVEY, D. (1989 [1973]), Urbanismo y desigualdad social, Madrid, Siglo XXI.

(1996), Justice, Nature \& the Geography of Difference, Malden, Blackwell.

KOOPMANS, R. (1995), Democracy from Below. New Social Movements and the Political System in West Germany, Colorado, Westview.

LEFEBVRE, H. (1975 [1968]), El derecho a la ciudad, Barcelona, Península.

(1976 [1970]), De lo rural a lo urbano, Barcelona, Península.

LOJKINE, J. (1980 [1977]), El marxismo, el Estado y la cuestión urbana, México, Siglo XXI.

LOWE, S. (1986), Urban Social Movements. The City after Castells, London, Macmillan.

MARTÍNEZ, M. (1999), "La traslación de estrategias empresariales al territorio: problemas de la Planificación Estratégica en el urbanismo", Política y Sociedad, nº 31.

(2002), Okupaciones de viviendas y centros sociales. Autogestión, contracultura y conflictos urbanos, Barcelona, Virus.

MAYER, M. (1993), "The Career of Urban Social Movements in West Germany", en R.Fisher, J.Kling (ed.), Mobilizing the Community. Local Politics in the Era of the Global City, California, Sage.

MCKAY, G. (ed.) (1998), DiY Culture. Party \& Protest in Nineties Britain, London, Verso.

NAVARRO, C.J. (1998), El nuevo localismo. Municipio y democracia en la sociedad global, Córdoba, Diputación de Córdoba.

PAKULSKI, J. (1991), Social Movements. The Politics of Moral Protest, Melbourne, Longmann.

PASTOR, J. (1998), "La evolución de los nuevos movimientos sociales en el Estado español" en P.Ibarra, B.Tejerina (ed.), Los movimientos sociales. Transformaciones politicas y cambio cultural, Madrid, Trotta.

PICKVANCE, Ch. (1975), "On the Study of Urban Social Movements", The Sociological Review, vol.23, $\mathrm{n}^{\circ} 1$.

(1985), "The rise and fall of urban movements and the role of comparative analysis", Environment and Planning D: Society and Space, vol.3.

(1986), "Concepts, contexts and comparison in the study of urban movements: a reply to M. Cstells", Environment and Planning D: Society and Space, vol.4. 
RIS

REVISTA INTERNACIONAL DE SOCIOLOCIA

No 34, Enero-Abril, 2003

MICUEL MARTÍNEZ LÓPEZ

(1994), "Teorías sobre planificación urbana e identificación de los efectos de dicha planificación" en A.Alabart et al. (comps.), Clase, poder y ciudadania, Madrid, Siglo XXI.

PICKVANCE, CH., E. PRETECEILLE (ed.) (1991), State Restructuring and Local Power. A Comparative Perspective, London, Pinter.

RIVAS, A. (1998), "El análisis de marcos: una metodología para el estudio de los movimientos sociales", en P.Ibarra, B.Tejerina (ed.), Los movimientos sociales. Transformaciones politicas y cambio cultural, Madrid, Trotta.

SAUNDERS, P. (1981), “Community Power, Urban Managerialism and the Local State” en M.Harloe (ed.), New Perspectives in Urban Change and Conflict, London, Heinemann.

(1986), Social Theory and the Urban Question, London, Hutchinson.

TARROW, S. (1997 [1994]), El poder en movimiento. Los movimientos sociales, la acción colectiva y la politica, Madrid, Alianza.

TOURAINE, A. (dir.) (1990), Movimientos sociales de hoy. Actores y analistas, Barcelona, Hacer.

URRUTIA, V. (1992), "Transformación y persistencia de los movimientos sociales urbanos", Politica y Sociedad, 10.

(1999), Para comprender qué es la ciudad. Teorias sociales, Estella, EVD.

VILLASANTE, T.R. et al. (1989), Retrato de chabolista con piso. Análisis de redes sociales en la remodelación de barrios de Madrid, Madrid, Alfoz-SGV-IVIMA.

(ed.) (1994), Las ciudades hablan, Caracas, Nueva Sociedad.

(1984), Comunidades locales. Análisis, movimientos sociales y alternativas, Madrid, IEAL.

(1995), Las democracias participativas. De la participación ciudadana a las alternativas de sociedad, Madrid, HOAC. 